\title{
An eco-friendly oxidation of sulfide compounds
}

\author{
RAVINDRA B WAGH, SITARAM H GUND and JAYASHREE M NAGARKAR* \\ Department of Chemistry, Institute of Chemical Technology, Matunga, Mumbai 400 019, India \\ e-mail: jm.nagarkar@ictmumbai.edu.in
}

MS received 22 March 2016; revised 11 May 2016; accepted 24 May 2016

\begin{abstract}
An improved green route has been developed for the oxidation of sulfide compounds. Albendazole is converted to ricobendazole or albendazole sulfone using $\mathrm{H}_{2} \mathrm{O}_{2}$ as an oxidant and $\mathrm{H}_{2} \mathrm{O}$ as the solvent. High yields of the corresponding products were obtained by carrying out the reaction at room temperature. This synthetic method is environmentally clean and safe, operationally simple for the oxidation of other benzimidazole anthelmintics and various sulfide compounds.
\end{abstract}

Keywords. Oxidation; sulfide; sulfoxide; sulfone; benzimidazole anthelmintic.

\section{Introduction}

Benzimidazoles are the bicyclic compounds with fused benzene and imidazole rings. ${ }^{1}$ Benzimidazole anthelmintics are the drugs which kill internal parasites from the body without causing significant damage to the host. $^{2}$ They are applied to treat people or animals which are infected by helminths. These drugs include albendazole, ricobendazole, albendazole sulfone, fenbendazole, oxfendazole, fenbendazole sulfone, etc. Ricobendazole is a very important metabolite of albendazole which acts as an anthelmintic. ${ }^{3}$ It is therapeutically a key anthelmintic agent with low bioavailability. ${ }^{4}$ Its low host toxicity and broad spectrum of activity against lungworms, tapeworms, and gastrointestinal nematodes have made it successful as anthelmintic agent. ${ }^{5,6}$ Albendazole sulfone is also used as scolicidal agents on hydatid cysts (in vitro study). ${ }^{7}$ Efficacies of albendazole sulfone against in vitro cultivated Echinococcus multilocularis Metacestodes was also studied. ${ }^{8}$

Here, we propose a green protocol for the oxidation of benzimidazole anthelmintics (Scheme 1) and also in general for sulfide to sulfoxide or sulfone compounds. Most of the principles of green chemistry are followed in this protocol such as use of $\mathrm{H}_{2} \mathrm{O}$ and $\mathrm{H}_{2} \mathrm{O}_{2}$ and ambient temperature. This process is more efficient than other reported methods regarding various aspects. $\mathrm{H}_{2} \mathrm{O}$ as a green solvent and $\mathrm{H}_{2} \mathrm{O}_{2}$ as an ideal "green" oxidant are used in this method. The process does not require any catalyst or acid with solvents or electrolysis technique as reported earlier. ${ }^{9-14}$ The yield of the products are high and $\mathrm{H}_{2} \mathrm{O}$ is generated as the only byproduct and

\footnotetext{
*For correspondence
}

no toxic byproduct is generated. This is a simple oxidation process and it is clean and safe to handle for large scale production of benzimidazole anthelmintics.

Numerous reagents and oxidative procedures are available for oxidation of sulfide compounds. Sulfoxides and sulfones are widely used in pharmaceuticals or petrochemicals. The classical idea was to perform the oxidation in homogenous medium but it is unsuitable if one of the substrates is insoluble in the reaction medium. All the reported methods gave good to better product yields as per their reaction conditions. However, they have some limitations such as requirement of variable temperature, reaction medium and use of toxic reagents. In some cases, transition metals were used as catalysts to achieve the desired yield of the product though these transition metals are not environmentally friendly and are very expensive. ${ }^{15-20}$ Our method is very simple, green and affords excellent yield of products.

\section{Experimental}

\subsection{Materials and Methods}

All chemicals were purchased from Sigma Aldrich, Loba Chemie, commercial suppliers and were used without further purification. Hydrogen peroxide solution of $30 \%$ and $50 \%$ were procured from SD Fine chemicals Ltd. The reaction was monitored by TLC, GC and LCMS. The products were characterized by LCMS (Varian Inc, USA Model: 410 Prostar Binary LC with 500 MS IT PDA Detectors) and GCMS (Shimadzu instrument (Rtx-17, $30 \mathrm{~m} \_25 \mathrm{~mm}$ ID, film thickness

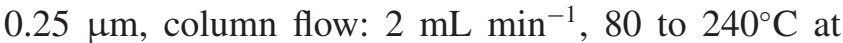
$10^{\circ} \mathrm{C} / \mathrm{min}$ rise). ${ }^{1} \mathrm{H}$ and ${ }^{13} \mathrm{C}$ NMR spectra were recorded 


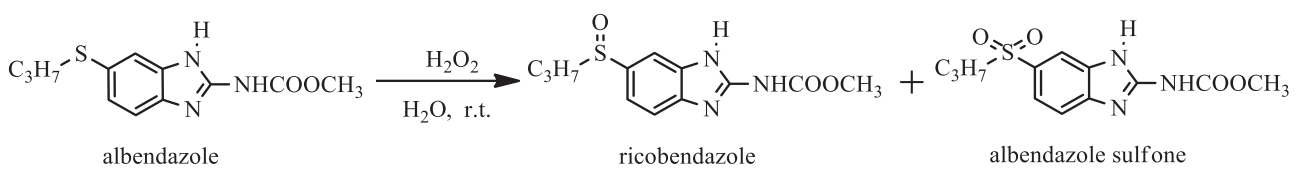

Scheme 1. Oxidation of albendazole.

Table 1. ${ }^{\mathrm{a}}$ Optimization of reaction parameters.

\begin{tabular}{|c|c|c|c|c|}
\hline & & ricobendazole & albenda & \\
\hline \multirow[t]{2}{*}{ Entry } & \multirow[t]{2}{*}{ Oxidant (equiv.) } & \multirow[t]{2}{*}{ Time (h) } & \multicolumn{2}{|c|}{$\operatorname{Yield}(\%)^{\mathrm{b}}$} \\
\hline & & & Sulfoxide & Sulfone \\
\hline 1 & $\mathrm{H}_{2} \mathrm{O}_{2} 50 \%(1.0)$ & 10 & 82 & - \\
\hline 2 & $\mathrm{H}_{2} \mathrm{O}_{2} 50 \%(1.2)$ & 8 & 100 & - \\
\hline 3 & $\mathrm{H}_{2} \mathrm{O}_{2} 50 \%(2.2)$ & 11.5 & 1 & 80 \\
\hline 4 & $\mathrm{H}_{2} \mathrm{O}_{2} 50 \%$ & 10 & - & 100 \\
\hline 5 & Peracetic acid (1.2) & 8 & 40 & 1.5 \\
\hline 6 & Peracetic acid (2.5) & 10 & 6 & 65 \\
\hline 7 & Oxone (1.2) & 8 & 33 & 0.8 \\
\hline 8 & Oxone (2.5) & 10 & 4.9 & 72 \\
\hline 9 & $\mathrm{H}_{2} \mathrm{O}_{2} 30 \%(1.2)$ & 15 & 100 & - \\
\hline 10 & $\mathrm{H}_{2} \mathrm{O}_{2} 30 \%$ & 21 & - & 100 \\
\hline
\end{tabular}

${ }^{a}$ Reaction conditions: albendazole $(1 \mathrm{mmol})$, oxidant, $\mathrm{H}_{2} \mathrm{O}(2 \mathrm{~mL})$, temp. $\left(30-35^{\circ} \mathrm{C}\right) ;{ }^{\mathrm{b}}$ conversion and yield determined by LCMS.

on a Varian Mercury plus-300 spectrometer at 400 and $100 \mathrm{MHz}$ in DMSO or $\mathrm{CDCl}_{3}$ as the solvent and TMS as an internal standard.

\subsection{General procedure for the oxidation of benzimidazole anthelmintics}

A mixture of alkyl or aryl derivative of albendazole ( $1 \mathrm{mmol}$ ) and $\mathrm{H}_{2} \mathrm{O}(2 \mathrm{~mL})$ was taken in a stoppered tube. Then $1.2 / 2.5$ equiv. of $50 \% \mathrm{H}_{2} \mathrm{O}_{2}$ was added slowly to it. The reaction mixture was stirred at room temperature for specified time. The progress of the reaction was monitored by TLCand $100 \%$ conversion of starting material on TLC was observed. All the reactants (starting materials) as well as products are insoluble in $\mathrm{H}_{2} \mathrm{O}$ and it was used just as medium for stirring. Therefore, the reaction mixture was filtered after completion of the reaction and the product was washed with distilled water followed by acetone and dried at $100^{\circ} \mathrm{C}$. The final product was analyzed by ${ }^{13} \mathrm{C},{ }^{1} \mathrm{H}$ NMR spectra.

\subsection{General procedure for the oxidation of sulfoxidel sulfone from sulfide compounds}

A mixture of sulfide $(1 \mathrm{mmol})$ and $\mathrm{H}_{2} \mathrm{O}(2 \mathrm{~mL})$ was taken in a stoppered tube. Then $1.2 / 2.5$ equiv. of $50 \%$ $\mathrm{H}_{2} \mathrm{O}_{2}$ was added slowly to it. The reaction mixture was stirred at room temperature. The progress of the reaction was monitored by TLC or GC. After $24 \mathrm{~h}$, the product was extracted with ethyl acetate $(3 \times 5 \mathrm{~mL})$. The organic layer was separated, dried $\left(\mathrm{Na}_{2} \mathrm{SO}_{4}\right)$, and concentrated under vacuum. The crude products were purified by column chromatography using silica gel (60-120 mesh) with petroleum ether and ethyl acetate as solvent to get the pure product. The pure products were analyzed by ${ }^{13} \mathrm{C},{ }^{1} \mathrm{H}$ NMR spectra and gas chromatography mass spectrometer (GCMS).

\section{Results and Discussion}

Initially, a model reaction was carried out using albendazoleas as substrate and $\mathrm{H}_{2} \mathrm{O}$ as solvent. It should be noted that $\mathrm{H}_{2} \mathrm{O}$ is used as the medium to facilitate the reaction. Oxidant plays a key role in this reaction. Therefore, the reaction was carried out with $\mathrm{H}_{2} \mathrm{O}_{2}$, peracetic acid and oxone as oxidants. $\mathrm{H}_{2} \mathrm{O}_{2}$ turned out to be the best oxidant as it gave $100 \%$ conversion of the products whereas other two oxidants afforded very low yield (Table 1, entries 1-8).

In further investigations, we carried out the model reaction with different amounts of $\mathrm{H}_{2} \mathrm{O}_{2}$. The reaction did not reach completion using less than 1.2/2.5 equiv. of $\mathrm{H}_{2} \mathrm{O}_{2}$ (Table 1, entries 1-4). As the concentration 
Table 2. ${ }^{\text {a }}$ Reaction of various subtrates of benzimidazole anthelmintics.

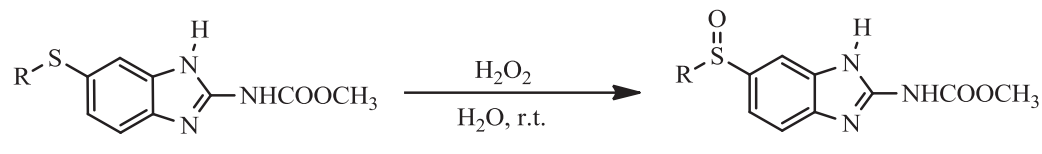

1

2

Entry

${ }^{\mathrm{a}}$ Reaction conditions: Substrate ( $\left.1 \mathrm{mmol}\right), \mathrm{H}_{2} \mathrm{O}_{2} 50 \%$ (1.2 equiv.), $\mathrm{H}_{2} \mathrm{O}(2 \mathrm{~mL})$, temp. $\left(30-35^{\circ} \mathrm{C}\right) ;{ }^{\mathrm{b}}$ Isolated yield.

Table 3. ${ }^{a}$ Reaction of various substrates of benzimidazole anthelmintics.

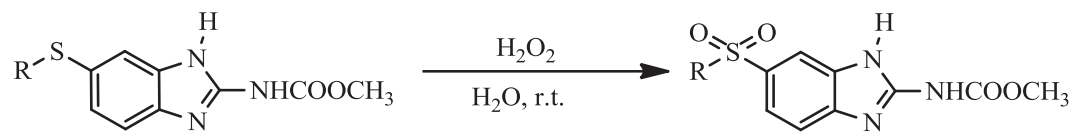

3

4

Entry Substrate

${ }^{a}$ Reaction conditions: Substrate ( $\left.1 \mathrm{mmol}\right), \mathrm{H}_{2} \mathrm{O}_{2} 50 \%$ (2.5 equiv.), $\mathrm{H}_{2} \mathrm{O}(2 \mathrm{~mL})$, temp. $\left(30-35^{\circ} \mathrm{C}\right) .{ }^{\mathrm{b}}$ Isolated yield. 
Table 4. ${ }^{a}$ Oxidation of other general sulfides to sulfoxide or sulfone compounds.

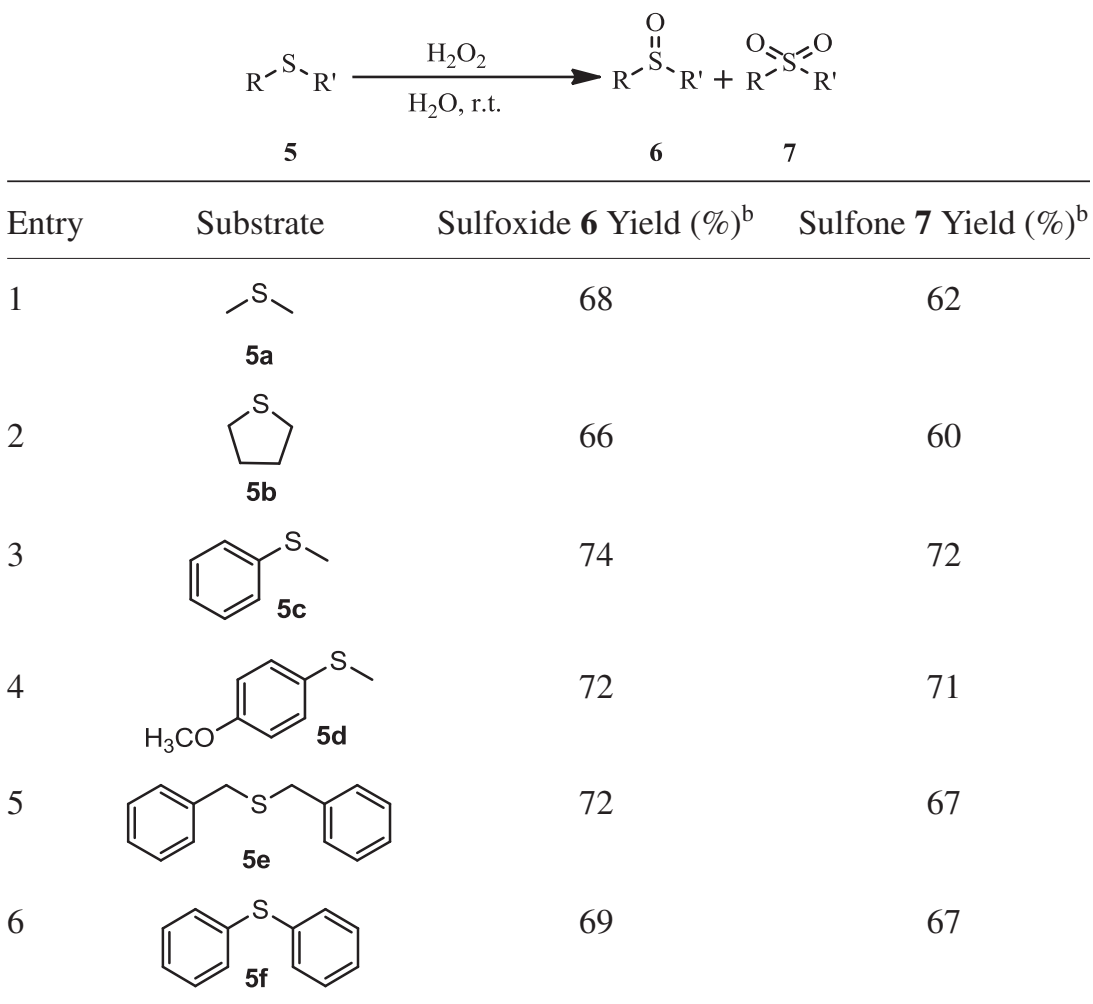

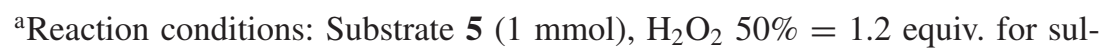
foxide 6, 2.5 equiv. for sulfone $7, \mathrm{H}_{2} \mathrm{O}(2 \mathrm{~mL})$, temp. $\left(30-35^{\circ} \mathrm{C}\right)$, time $=24 \mathrm{~h}$. ${ }^{\mathrm{b}}$ Isolated yield.

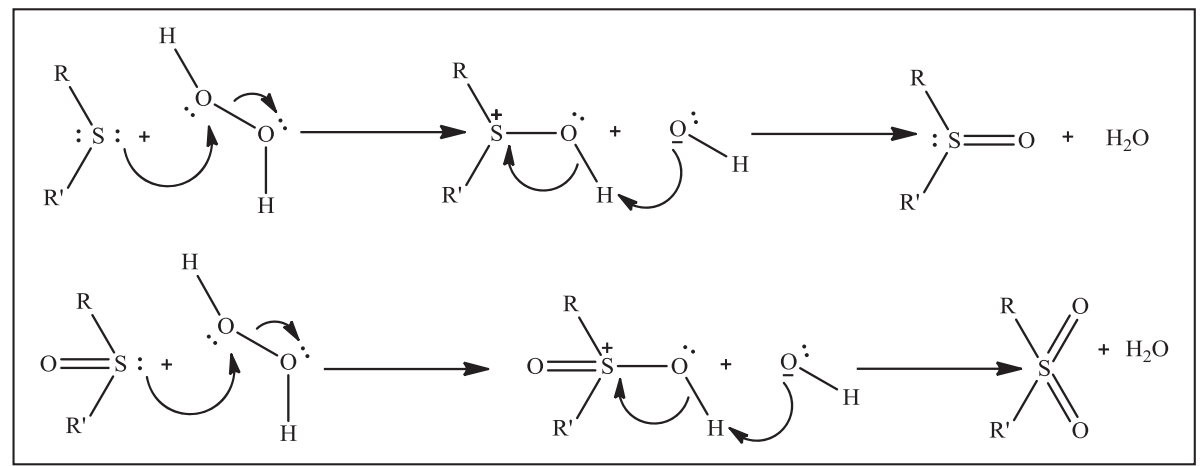

Figure 1. Plausible mechanism for the oxidation of sulfide compound.

of $\mathrm{H}_{2} \mathrm{O}_{2}$ was increased to $1.2 / 2.5$ equiv., the time for completion of reaction decreased with increased yield (Table 1, entries 2 and 4).

Sulfoxide is formed during the oxidation of sulfide to sulfone which is less nucleophilic. Therefore the said oxidation requires higher time as rate of oxidation of sulfoxide to sulfone is slow. Hence use of excess $\mathrm{H}_{2} \mathrm{O}_{2}$ (2.5 equiv.) in the reaction led to the corresponding sulfone via a clean reaction. The oxidation was investigated in various solvents but $\mathrm{H}_{2} \mathrm{O}$ was found to be the most suitable one. Model reaction was also carried out using $30 \% \mathrm{H}_{2} \mathrm{O}_{2}$ in $\mathrm{H}_{2} \mathrm{O}$ at room temperature which gave $100 \%$ yield, however the time required for this conversion was longer as compared to $50 \%$ $\mathrm{H}_{2} \mathrm{O}_{2}$ (Table 1, entries 9 and 10).

We also carried out oxidation of starting materials containing other alkyls and aryl derivatives of benzimidazoles (Tables 2 and 3) under optimized conditions. The method can be extended to other benzimidazole anthelmintics affording excellent yields. There is no significant effect on the yield of products regarding alkyl or aryl derivative of benzimidazoles. 
In order to explore the generality for this protocol, we further tested this selective oxidation with various sulfides and the results are presented in Table 4. Aliphatic and aromatic sulfides were treated with $50 \% \mathrm{H}_{2} \mathrm{O}_{2}$ and $\mathrm{H}_{2} \mathrm{O}$. We obtained the desired sulfoxides or sulfones (Table 4, entries 1-6). Dimethyl sulfide (5a) was oxidized to sulfoxide (6a) or sulfone (7a) under optimized reaction conditions (Table 4, entry 1 ). We have also oxidized tetrahydrothiophene $(\mathbf{5 b})$ to corresponding sulfoxide (6b) or (7b) with good yield (Table 4, entry 2). Notably, aryl or diaryl sulfides, with or without aromatic rings bearing electron donating groups, were also converted to their sulfoxides or sulfones under optimized reaction conditions (Table 4, entries 3-6). This indicates that the present protocol is very selective and easily controllable.

Although the precise mechanism of this transformation is still uncertain, the oxidation probably involves the nucleophilic attack of the sulfur on the peroxide oxygen atom (Figure 1). The products (Tables 2 and 3 ) were characterized by ${ }^{13} \mathrm{C},{ }^{1} \mathrm{H}$ NMR spectroscopy along with liquid chromatography mass spectrometer (LCMS). Also, the products (Table 4) were characterized by ${ }^{13} \mathrm{C}$, ${ }^{1} \mathrm{H}$ NMR spectroscopy and gas chromatography mass spectrometry (GCMS). Results confirmed the formation of desired products. The experimental molecular weights matched with those of standard molecular weights of the desired products.

\section{Conclusions}

In conclusion, a selective, controllable, cost effective, mild and highly efficient procedure was developed for the oxidation of synthetically important benzimidazole anthelmintics and other sulfides. The developed protocol can be considered as environmentally friendly as it avoids use of toxic oxidizing agent and other solvents and do not produce any hazardous byproducts as well. The corresponding products can be isolated in good to excellent yields under metal-free conditions. The transformation worked well with the solid and liquid sulfides in spite of a heterogeneous reaction mixture. The reaction operation is simple, easy to handle and it is suitable for large scale industrial production. High generality of substrates demonstrate promise in broad applications of this protocol in organic synthesis.

\section{Supplementary Information (SI)}

Supplementary Information is available at www.ias.ac. in/chemsci.

\section{Acknowledgements}

Financial support from UGC, India for a research fellowship under BSR-SAP scheme is gratefully acknowledged.

\section{References}

1. (a) Yu B, Zhang H, Zhao Y, Chen S, Xu J, Huang C and Liu Z 2013 Green Chem. 15 95; (b) Olivier J, Christophe D N G, Michel E and Thibault C 2013 ChemCatChem 5117

2. (a) Zhang Y, Huang X and Yuan D 2015 Anal. Bioanal. Chem. 407 557; (b) Krizova-Forstova V, Lamka J, Cvilink V, Hanusova V and Skalova 2011 Res. Vet. Sci. 91333

3. Fazzioa L E, Sánchezb R O, Streitenbergera N, Galvana W R, Giudicic C J and Gimenoa E 2014 Vet. Parasitol. 206240

4. Formentini E, Mestorino A and Errecalde N J O 2005 Vet. Res. Commun. 29595

5. Wu Z, Razzak M, Tucker I G and Medlicotti N J 2005 J. Pharm. Sci. 94983

6. Canan K and Nurten A 2003 Turk. J. Chem. 2735

7. Adas G, Arikan S, Kemik O, Oner A, Sahip N and Karatepe O 2009 World J. Gastroenterol. 15112

8. Ingold K, Bigler P, Thormann W, Cavaliero T, Gottstein B and Hemphill A 1999 Antimicrob. Agents Chemother. 431052

9. Dai W, Li G, Wang L, Chen B, Shang S, Lv Y and Gao S 2014 RSC Adv. 446545

10. Stalder R and Roth G P 2013 ACS Med. Chem. Lett. 4 1119

11. Haugwitz R D and Cruthers L R 1978 Method of treating helminthiasis by parenteral administration of sulfoxide derivatives of benzimidazoles U.S. Patent 4076827

12. Haugwitz R D and Cruthers L R 1978 Method of treating helminthiasis by parenteral or topical administration of sulfoxide derivatives of benzimidazoles U.S. Patent 4076827

13. Wang Y, Pan Z and Dai X 2004 Method for preparing liquor pharmaceutics containing alendazole sulfoxide CN Patent 1518980 (A)

14. Lachhein S, Mildenberger $\mathrm{H}$ and Ressel H-J 1988 Process for the preparation of 5-Penylsulfinyl-1H-2(Methoxycarbonylamino)-benzimidazole U. S. Patent 4792610

15. Egami H and Katsuki T 2007 J. Am. Chem. Soc. 129 8940

16. Frenzel R A, Romanelli G P, Blanco M N and Pizzio L R 2015 J. Chem. Sci. 127123

17. Maity P, Mukesh D, Bhaduri S and Lahiri G K $2009 \mathrm{~J}$. Chem. Sci. 121377

18. Kon Y, Yokoi T, Yoshioka M, Tanaka S, Uesaka Y, Mochizuki T, Sato K and Tatsumi T 2014 Tetrahedron 707584

19. Drago C, Caggiano L and Jackson R F W 2005 Angew. Chem. Int. Ed. $\mathbf{4 4} 7221$

20. Dai W, Li J, Chen B, Li G, Lv Y, Wang L and Gao S 2013 Org. Lett. 155658 